Keywords: Primary health care, Mental health, Review, Training.

\title{
General practitioners are bearing an increasing burden of the care of common mental disorders in France
}

\author{
Joanna Norton* \\ Michel David ${ }^{* *}$ \\ Jean-Philippe Boulenger ${ }^{\star, * * *}$ \\ * Inserm, U888, Montpellier, F-34093; Univ \\ Montpellier I, Montpellier, F-34000 \\ ** Department of General Practice, Univ \\ Montpellier I, Montpellier, F-34000 \\ *** CHU Montpellier, Hop La Colombière / \\ Department of Adult Psychiatry, Montpellier, \\ F-34093 \\ FRANCE
}

\begin{abstract}
Introduction: In France, general practice is playing an increasing role in the management of common mental disorders. This is due to a variety of factors, among which the way general practice and specialised mental health services have evolved over time.

Methods: Method: A description of the status quo in France, with a comparison between France, the UK and the Netherlands. A review of reasons for the present position.

Results: The general practitioner (GP) is often the only medical carer to be contacted in cases of psychological distress and over $80 \%$ of psychotropic medications are prescribed in this setting. Although most common forms of mental disorder can be managed at the primary care level, GPs need to be able to refer patients rapidly to specialised mental health services. Yet there are delays for consultations with both private and public psychiatrists along with difficulties in finding beds for full-time hospitalisation. The situation is predicted to get worse with the reduction in the number of psychiatrists and GPs forecasted for the coming years. 'Psychiatric sectorisation' has led to a substantial development of community mental health care services, yet this has not compensated fully for the reduction in full-time hospital beds. Furthermore, community mental health care services remain relatively isolated from other community health services with very limited exchanges with general practice.

Conclusion: GPs report an urgent need for training in mental health. Along with improving their ability to accurately detect and treat mental disorders, it is crucial also to improve communication between GPs and psychiatrists and increase shared case-management. Structural changes are also necessary to ensure a quicker and easier access to specialised mental health care services.
\end{abstract}


General practice in France is increasingly at the forefront for the management of common mental disorders (mainly anxiety and depression). This is due to a variety of factors linked mainly to the way general practice and psychiatry have evolved over time, a lack of coordinated care between generalist and specialist physicians and a of communication between general practice and community specialised mental health care. After describing the current situation of general practice as well as specialised psychiatric services, this paper will examine how general practice fits in to mental health care in France and the options the general practitioner (GP) has to choose from when managing mental illness.

\section{French general practice}

General practice in France contrasts to that in many other European countries. Firstly, France has one of the highest numbers of GPs per head of population ${ }^{1}$. Yet projections predict a $25 \%$ reduction in the number of GPs by $2025^{2}$. As for all health care facilities in France, there are huge geographical disparities with a lack of physicians practicing in the rural areas and the North and a concentration of physicians in the Paris area and the Mediterranean urban zones $^{3,5}$. This results from the freedom of choice to set up practice almost anywhere irrespective of the density of physicians in the area.

In France, GPs work as private practitioners on a fee for service basis with patients being paid back fully or partly by the state insurance system. GPs work mainly alone with no ancillary staff and with little contact with other GPs and specialists. Patients were until recently free to consult directly any GP or specialist (private or public) as often as wanted. Since July 2005, every citizen is encouraged to register with a specific physician (in $98 \%$ of cases a GP is chosen), responsible for coordinating care and referring patients to specialists ${ }^{6}$. This measure is hoped to reduce the amount of "shopping around" done by patients and overbooking of costly specialist services by patients with erroneously "self-diagnosed" disorders. Visits to most specialists without referral from the coordinating doctor are financially sanctioned.

Although direct visits to specialists have decreased dramatically ${ }^{7}$, this new legislation has substantially increased GPs' workload. Furthermore, patients being allowed to choose a GP or a specialist as coordinating physician and change at will, GPs have not been given a clear gate-keeping role restricting access to specialists as in the UK for example. They are regularly faced with the dilemma of complying with patients' demands which is in their interest and ethical considerations. The main differences between the organisation of general practice in France and in two contrasting European countries, the UK and the Netherlands, is shown in Table I.

In France, as elsewhere ${ }^{8}$, the GP is often the first and only medical professional to be contacted in the case of mental illness ${ }^{9}$. It is now widely acknowledged that GPs play a key role in the early identification of mental disorders and for severe cases in reducing the delay to appropriate treatment. Furthermore over $80 \%$ of all psychotropic medication prescriptions emanate from general practice $^{10,11}$. Mental illness accounts for approximately one third of all health problems presented to the $\mathrm{GP}^{12,13}$ and is likely to increase hand in hand with the increase of common mental disorders in the general population. 
Yet GPs report that they have very little time to deal with psychological problems which already account for longer consultation times ${ }^{14,15}$ than the 15 minute average ${ }^{16}$. Despite recent changes introducing additional fees for specific procedures ${ }^{17}$, the type of consultation and the corresponding amount of time required are not taken into account meaning a fixed rate is charged whatever the length of the consultation. GPs report a lack of initial training in mental health and over two-thirds of them state a need for continuous medical education training specifically in case-detection and psychotherapy ${ }^{18}$. Prescribing psychotropic medication often remains the only immediate solution. It is a safe "refuge" for GPs faced alone with complex clinical pictures and pushed to the limits of their medical competences $^{19}$.

It is widely acknowledged that French GPs, as elsewhere, recognise approximately half of cases of psychiatric disorder among their patients ${ }^{12,13}$, as diagnosis is often made difficult by comorbid physical illness and patients presenting with somatic symptoms only. It has been shown that half of cases of major depression go unnoticed ${ }^{12}$ and less than half receive adequate treatment ${ }^{9}$. Improving GPs' ability to establishing accurate psychiatric diagnoses and offer adequate treatment is important ${ }^{11}$ just as is easy and rapid access to specialised care.

\section{Specialised mental health care services}

In France, there are a variety of different mental health services: the public hospital sector-offering inpatient beds in psychiatric hospitals and general hospitals, part-time (day or night) outpatient places, consulta- tions and ambulatory mental health care private and semi-private psychiatric clinics and private psychiatric practices.

In 2004, France reported 14,000 psychiatrists, that is 22 for 100,000 inhabitants, which is the highest density of psychiatrists in Europe ${ }^{20} .47 \%$ of psychiatrists are private. However, $49 \%$ of psychiatric establishments and $73 \%$ of psychiatric beds are in the public sector ${ }^{21}$. There are strong regional disparities with the highest density of psychiatrists found in urban centres (especially those with teaching hospitals) and in the southern part of the country. A large number of posts for psychiatrists in the state health system's hospitals lie vacant, especially in the rural areas and in northern France $^{22}$.

Since the 1960s, state hospital services are organised into geographic 'sectors' each covering a population of approximately 70,000. The aim of this "politique de secteur" is to limit full-time hospitalisation and develop a variety of structures in the community such as out-of-hospital consultation and day care centres, therapeutic workshop centres and home-visits, as well as continuity of care with the same mental health care team ${ }^{23,24}$. It is also to develop coordinated mental health care involving primarily GPs. Although the extension of psychiatric hospital care into the community has been substantial, there are huge disparities between sectors in the transition from hospital care to ambulatory care leading to different specialised care models in different $\operatorname{areas}^{23}$. Table I shows the main differences between the organisation of specialised mental health care services in France and two contrasting European countries.

Since the 1990s, there have been further large reductions in the number of psychiatric hospital beds and in the mean duration 


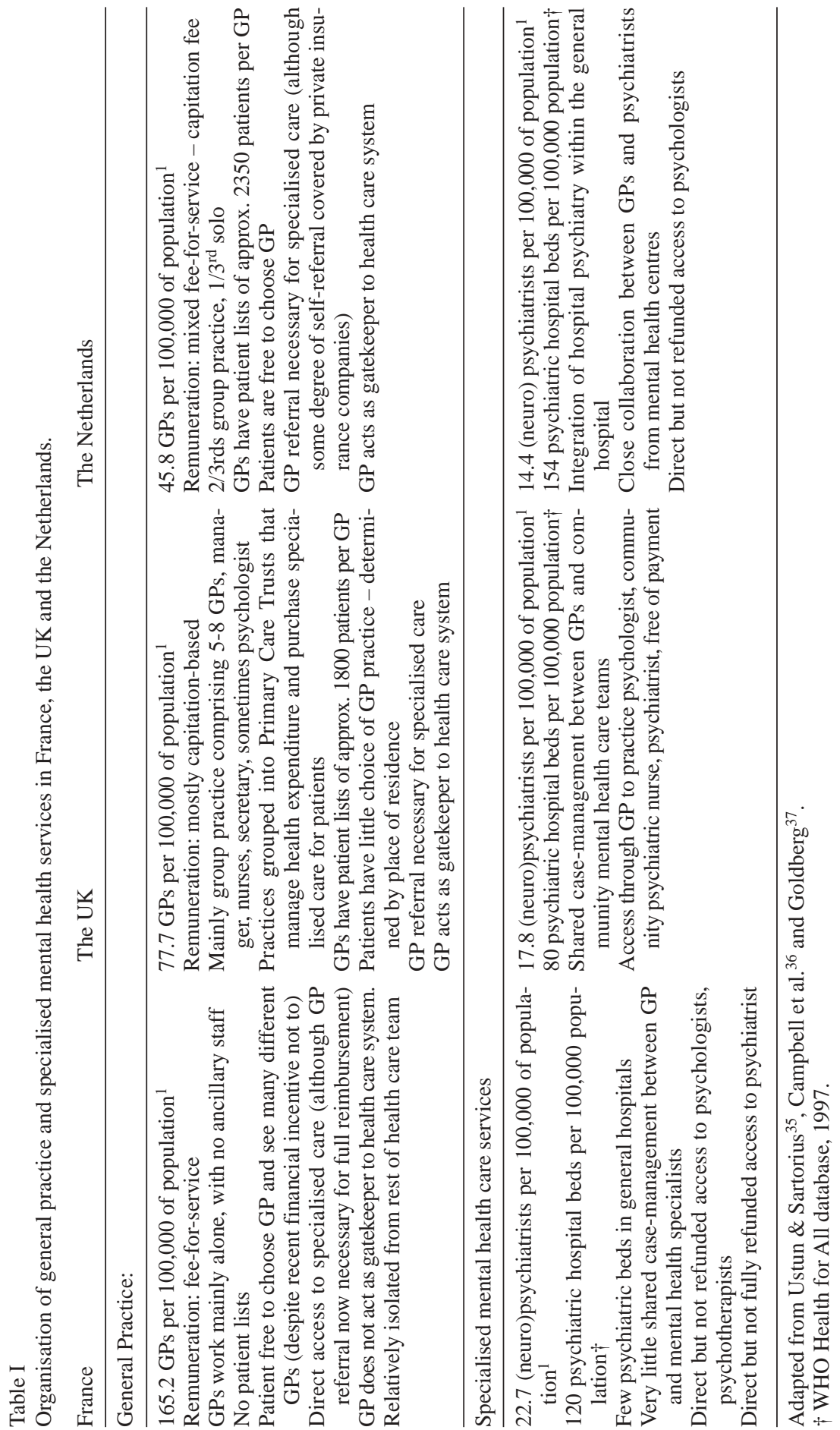


of stay $^{22,24}$, leading to frequent readmissions after discharge of patients not sufficiently stabilised. These cuts were meant to be compensated for by an even greater development of ambulatory care. Although this varies form one sector to another, it has overall been insufficient, with less than $10 \%$ of total mental health expenditure used on public sector community care . $^{3}$

\section{Forecasted reductions in the number of psychiatrists}

Owing to the drastic reduction in the number of medical students since the 1980s (numerus clausus), the number of psychiatrists should decrease by nearly $40 \%$ over the next two decades. This should theoretically be sufficient to ensure France's mental health needs ${ }^{25}$ as it will be comparable to that of other European countries. However, there are already huge disparities in staff and bed resources from one sector to another and inequalities in access to care are likely to worsen, especially if private psychiatry remains unregulated with the possibility of setting up practice anywhere ${ }^{22}$. Moreover, a large number of private practitioners are principally practicing psychoanalytically orientated psychotherapy ${ }^{26}$.

\section{The un-bridged gap between general practice and specialised mental health services}

Let alone the time constraints of the feefor-service system, French GPs are confronted with difficulties in accessing spe- cialised care that have worsened with the above-mentioned changes.

The GPs in Verdoux et al's study report long yet similar delays for booking consultations with both public and private psychiatrists for patients with an early onset of schizophrenia. GPs obtained a consultation with a psychiatrist, whether private or public, in less than two weeks for only $40 \%$ of patients $^{27}$. Delays can be expected to be even longer for less severe non-psychotic disorders and to increase in coming years with the forecasted drop in the number of psychiatrists.

The long appointment delay for consulting private psychiatrists can be explained partly by the fact that most patients are seen on a very frequent basis for psychoanalytical therapy only ${ }^{26,28}$. Private psychiatrists very rarely offer alternative therapies ${ }^{26}$. They see many patients with personal problems or sub-threshold symptoms only, leaving little time for new patients with definite psychiatric disorders ${ }^{28,29}$.

Despite similar consultation delays, GPs are more likely to refer patients with early onset schizophrenia to private psychiatrists ${ }^{27}$. It is likely that this applies even more so to patients with common disorders. Yet, private psychiatrists often charge rates beyond what is covered by the national health insurance, requiring patients with no additional private health insurance to pay the difference. When offering psychoanalytic therapy, the entire fee is often to be paid by the patient as part of the treatment process. Patients managed in the public 'sector' whether in full-time hospitalisation or ambulatory care tend to cumulate other medical and social problems: physical health problems, unemployment, marital problems and poor functioning. This 'patient environment' may no doubt make GPs reluctant to contact public sector psy- 
chiatrists for their patients ${ }^{29}$. GPs most often choose to manage patients in the early stages of mental disorder in general practice. The reluctance to refer them to a psychiatrist comes not only from the long consultation delay but from the complex procedure for booking a consultation. In order to actually be given an appointment it is often the GP who contacts the psychiatrist: for many GPs this involves ringing the psychiatrist and leaving a message on an answer phone (most private psychiatrists work alone with no secretary), being rung back by the psychiatrist, fixing the appointment and then contacting the patient again.

Advising a patient to visit a psychologist can sometimes avoid the stigma attached to seeing a psychiatrist and reduce the length of time necessary to convince the patient to consult. As is the case for private psychiatrists, psychologists offer mainly psychoanalytical therapy. However consultations are never refunded which explains in part why GP patient referral is limited ${ }^{27}$. French psychologists see mainly children and adolescents; the small proportion of adults consulting them tends to have perturbed personal and professional lives rather than clear-cut psychiatric disorders, coupled with a high level of education ${ }^{29}$.

Psychotherapies are offered at large in France as there is no convention regulating training and access to the profession (today anybody is entitled to offer psychotherapy). Increasing access to psychotherapies, by structuring the profession (setting official rules for being labelled as a 'psychotherapist') and examining how the costs could be covered by the national health insurance system, is currently under discussion ${ }^{30}$.

When requiring in-patient hospital care for a patient, both private clinics and public psychiatric hospitals pose problems. Private clinics often charge beyond what is covered by the national health insurance. Regarding hospital services, GPs are often confronted with difficulties in obtaining rapid full-time admission for a patient due to the reduction in hospital beds, a quicker "way in" being sometimes through the emergency services. Furthermore, a patient will preferentially be placed in the sector corresponding to his place of residence. As mentioned above, there are huge disparities between sectors in the offer and quality of care, as well as the theoretical approach to care. Although in theory the rules of 'sectorisation' do not apply to the patient who can choose to be treated by a team other than the one in charge of the catchment area ${ }^{22,24}$, it is wellknown that the choice of the sector is very rarely left up to the patient ${ }^{24}$.

Public psychiatric care has remained relatively isolated with respect to other health care services. Firstly, there are very few psychiatric services in general hospitals and secondly, although the extension of psychiatric care out of the hospital into the community has been substantial, it remains relatively isolated from other community health care services. This has led to a lack of exchanges with other actors of the health care system ${ }^{24}$. GPs for example, report no or very infrequent contacts with their local mental health care teams although the vast majority know at least one private psychiatrist or psychiatrist of the sector's mental health care team $^{27}$. Furthermore GPs report a lack of feedback from psychiatrists regarding the diagnosis and treatment of patients they have referred $^{27,28}$. They also consider that irrespective of the diagnosis, the relationship with psychiatrists is difficult ${ }^{18}$, even more so than with other specialists ${ }^{28}$. Coordinated care and shared case-management will only be achievable if communication between GPs and psychiatrists is improved. 


\section{Conclusion}

The current trends in medical demography and the lack of coordinated care between GPs and psychiatrists, means that GPs are likely to become increasingly isolated in the management of common mental disorders. The French authorities are well aware of the "time-bomb" related to mental illness which will be increasingly difficult to cope with given the reduction in offer of specialised mental health care ${ }^{31}$.

As is the case for all drug consumption, France has one of the highest psychotropic drug consumption levels in Europe ${ }^{32,34}$, with over three quarters of prescriptions emanating from general practice ${ }^{11}$. A recent report points to the need to increase GPs' ability to accurately identify cases of psychiatric disorder and offer adequate treatment ${ }^{11}$. Increasing access to psychotherapies has also been highlighted as a priority ${ }^{30}$. The central role of general practice in the management of mental illness is clearly recognised. Yet, let alone improving accurate GP case-identification and treatment, developing communication and shared case-management between GPs and psychiatrists with better access to specialised care is crucial for France to tackle this growing public health problem.

\section{References}

1. Eurostat. Registered medical specialists - Absolute numbers and rates per 100,000 of population - 2003. Eurostat (New Cronos Database); 2003.

2. Caisse Autonome de Retraite des Médecins de France. Les vrais chiffres de la démographie des médecins libéraux. Caisse Autonome de Retraite des Médecins de France; 2006.
3. Direction de la Recherche, des Etudes, de l'Evaluation et des Statistiques. Données sur la situation sanitaire et sociale en France en 2002. Direction de la Recherche, des Etudes, de l'Evaluation et des Statistiques, Ministère des affaires sociales, du travail et de la solidarité, Ministère de la santé, de la famille et des personnes handicapées; 2002.

4. Imai Y, Jacobzone S, Lenain P. The changing health system in France. Economics Department Working paper \# 269. Organisation for Economic Cooperation and Development (OECD); 2000.

5. Vigneron E. Quelques coupes à travers le corps médical français. Actualités et Dossiers en Santé Publique 2000; 32: 19-21.

6. Assurance Maladie. http://www.assurancemaladie. sante.gouv.fr/: comprendre la réforme point par point. Paris, France; 2005.

7. Caisse Nationale de l'Assurance Maladie. Médecin traitant et parcours de soin coordonnés: premier bilan. Point d'Information Mensuel, le 6 juin 2006; 2006.

8. Goldberg DP, Huxley P. Common Mental Disorders: A Bio-Social Model. London and New York; 1992.

9. Lepine JP, Gastpar M, Mendlewicz J, Tylee A. Depression in the community: the first pan-European study DEPRES (Depression Research in European Society). Int Clin Psychopharmacol 1997; 12(1): 19-29.

10. Baumann M, Alla F, Empereur F. Psychotropes et Dépendances: Profils des Consommateurs et Trajectoires de leurs comportement. Paris, OFDT: Observatoire des Drogues et des Toxicomanies; 2001.

11. Briot M. Rapport sur le bon usage des médicaments psychotropes. Office Parlementaire d'Evaluation des Politiques de Santé (OPEPS); 2006.

12. Lecrubier Y, Boyer P, Lepine J, Weiller E. Results from the Paris Centre. In: T. B. Ustun and N. Sartorius, editors. Mental Illness in General Health Care. An International Study. Chichester: John Wiley \& Sons; 1995.

13. Norton J, de Roquefeuil G, Benjamins A, Boulenger JP, Mann A. Psychiatric morbidity, disability and service use amongst primary care attenders in France. Eur Psychiatry $2004 ; 19(3)$ : 164-7.

14. Breuil-Genier P, Goffette C. La durée des séances des médecins généralistes. Direction de la Recherche, des Etudes, de l'Evaluation et des Statistiques (DREES) Etudes et Résultats 2006; 481.

15. Labarthe G. Les consultations et visites des médecins généralistes: un essai de typologie. Direction de la Recherche, des Etudes, de l'Evaluation et des Statistiques (DREES). Etudes et Résultats 2004; 315. 
16. Ustun TB, Von Korff M. Primary Mental Health Services: Access and Provision of Care. In: Ustun T B; Sartorius N, eds. Mental Illness in General Health Care. An International Study. Chichester: John Wiley \& Sons; 1995.

17. Caisse Nationale de l'Assurance Maladie. Nomenclatures des actes en médecine générale: version applicable au 1er juillet 2006. Caisse Nationale de l'Assurance Maladie; 2006.

18. Verger P. Déterminants de l'hétérogénéité des pratiques de prise en charge des problèmes de santé mentale en médecine de ville: étude des prescriptions d'antidépresseurs par les médecins généralistes de la région ProvenceAlpes-Côte d'Azur (PACA). Colloque "Représentations des troubles psychiques, pratiques de soins et vécu des malades". Paris; 2006.

19. Haxaire C. Représentation de la santé mentale et de la souffrance psychique par les médecins généralistes (Finistère et Côtes d'Armor). Colloque "Représentations des troubles psychiques, pratiques de soins et vécu des malades". Paris; 2006.

20. European Commission. The state of mental health in the European Union; 2004.

21. Coldefy M. Les disparités départementales de prises en charge de la santé mentale en France. Direction de la Recherche, des Etudes, de l'Evaluation et des Statistiques Etudes et Résultats 2005. P. 443.

22. Verdoux H, Tignol J. Focus on psychiatry in France. Br J Psychiatry 2003; 183: 466-471.

23. Guilmin A. "L'offre de soin en psychiatrie: des "modèles" diffférents selon les départements." DREES: Direction de la Recherche, des Etudes, de l'Evaluation et des Statistiques. Etudes et Résultats 2000. P. 48.

24. Reynaud M, Gallot AM, Lefèvre L. La politique de santé mentale en France. In: V. Kovess, Lopez A, Pénochet JC, Reynaud M. Psychiatrie années 2000: Organisations, Evaluations, Accréditation. Paris: Médecine-Sciences, Flammarion; 1999.

25. Piel E, Roelandt J. Rapport de Mission. De la Psychiatrie à la Santé Mentale. Paris: Ministère de l'Emploi et de la Solidarité, Ministère Délégué à la Santé; 2001.

26. Lafitte C, Martin C, Grabot D, Tignol J. A survey of private practice psychiatrist's training and activity in activity in Aquitaine, France, in 1993. Encephale1996; 22(6): 417-421.

27. Verdoux H, Cougnard A, Grolleau S, Besson R, Delcroix F. A survey of general practitioners' knowledge of symptoms and epidemiology of schizophrenia. Eur Psychiatry 2006; 21(4): 238-244.

28. Réseau de Promotion pour la Santé Mentale 78. Rapport de l'enquête 2000 du Réseau de Promotion pour la
Santé Mentale dans les Yvelines Sud. La Lettre de Promotion Santé Mentale Yvelines Sud 4; 2003.

29. Chapireau F. Les recours aux soins spécialisés en santé mentale. DREES: Direction de la Recherche, des Etudes, de 1'Evaluation et des Statistiques - Etudes et Résultats 2006; 533.

30. Clery-Melin P, Kovess V, Pascal JC. Plan d'actions pour le développement de la psychiatrie et la promotion de la santé mentale. Rapport d'étape de la mission CleryMelin remis au ministre de la santé, de la famille et des personnes handicapées; 2003.

31. Plan Psychiatrie et Santé Mentale 2005-2008. http://www.santé.gouv.fr.

32. Alonso J, Angermeyer MC, Bernert S, Bruffaerts R, Brugha TS, Bryson $\mathrm{H}$ et al. Psychotropic drug utilization in Europe: results from the European Study of the Epidemiology of Mental Disorders (ESEMeD) project. Acta Psychiatr Scand Suppl 2004; (420): 55-64.

33. Ohayon MM, Lader MH. Use of psychotropic medication in the general population of France, Germany, Italy, and the United Kingdom. J Clin Psychiatry 2002; 63(9): 817-825.

34. Tylee A, Gastpar M, Lepine JP, Mendlewicz J. DEPRES II (Depression Research in European Society II): a patient survey of the symptoms, disability and current management of depression in the community. DEPRES Steering Committee. Int Clin Psychopharmacol 1999; 14 (3): 139-151.

35. Ustun TB, Sartorius N. Mental Illness in General Health Care. An International Study. ed. Chichester: John Wiley \& Sons; 1995.

36. Campbell J, Mendive J, Timmermans A. Primary care and general practice in Europe: West and South. In: Jones R, Britten N, Culpepper L, Silagy C, Gass D. Oxford Textbook of Primary Medical Care. ed. Oxford: Oxford University Press; 2004.

37. Goldberg DP. Psychiatry and primary care. World Psychiatry 2003; 2(3): 153-157.

38. Simon M \& Niel X. Les effectifs et la durée du travail des médecins au 1er janvier 1999. DREES: Direction de la Recherche, des Etudes, de l'Evaluation et des Statistiques - Etudes et Résultats 1999; 44.

Address for correspondence:

Joanna Norton

Inserm U888, Hôpital La Colombière

Pavillon 42, 39 av. Charles Flahault

BP 34493, 34093 Montpellier Cedex 5 France

Tel : 0033 (4) 99614570 Fax : 0033 (4) 99614579

Norton Joanna : norton@montp.inserm.fr 